\title{
Ekelgefühle in der Arztpraxis: ertragen, bekämpfen, vermeiden
}

\author{
Dieser MMW-Ausgabe liegt wieder „info praxisteam“ bei, das Magazin für Medizinische Fachangestellte. \\ Ein Hauptthema in Heft 1/17 ist der Umgang mit Ekelgefühlen im Praxisteam. Eklige Substanzen und \\ Gerüche sind in der Patientenversorgung Alltag - hier gibt es Tipps für den richtigen Umgang.
}

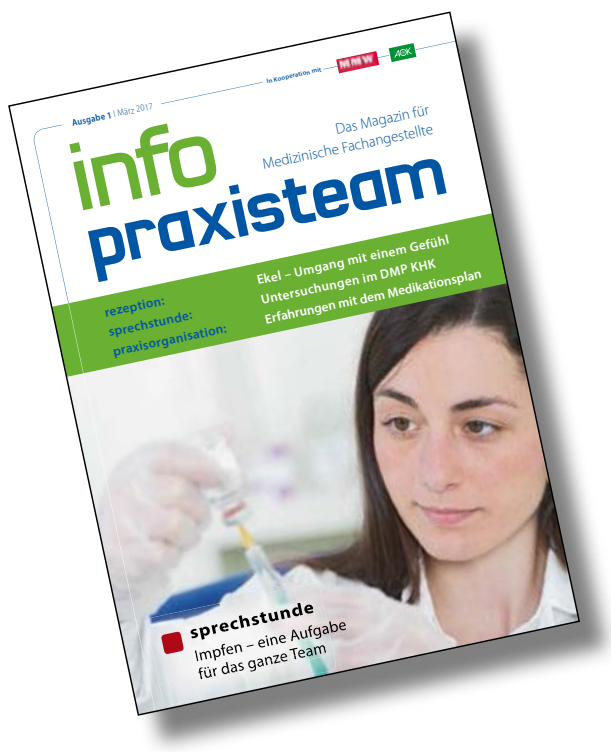

_ Der Geruch von Eiter bei der Behandlung eines Abzesses, eine blutige Urinprobe oder die mangelnde Hygiene eines Patienten - in einer Praxis gibt es viele Dinge, vor denen man sich ekeln kann. Und das betrifft Ärzte und Assistenzpersonal gleichermaßen. Der Einstiegsbeitrag der aktuellen Ausgabe von „info praxisteam “ beschäftigt sich daher mit dem Thema Ekel-Management.

Ekel entsteht in der Amygdala. Hier werden sensorische Signale mit Gedächtnisinhalten und Emotionen verknüpft und in konkrete Handlungen umgesetzt. Für die typischen physiologischen Ekelreaktionen wie Speichelfluss, Würgreiz und Erbrechen ist das Brechzentrum im verlängerten Rückenmark zuständig. Als Teil des vegetativen Nervensystems ist es nur sehr schwer zu beeinflussen.

Die Fähigkeit zum Ekel wird größtenteils erst im Lauf des Lebens erworben. Kleinkinder spielen durchaus auch mit vollen Windeln oder stecken auf dem Spielplatz Würmer in den Mund, ohne sich zu ekeln. Auch auf unangenehme Gerüche reagieren Kleinkinder nicht. Erst mit 3-5 Jahren entwickeln sie ein Bewusstsein für sauber und unsauber.

Da Ekel durch die Verbindung von Reizen und Erinnerungen entsteht, kann man sich ein Stück weit auch an ihn gewöhnen. Die sensorischen Informationen werden dann zwar weiterhin wahrgenommen, doch der emotionale Gehalt nimmt ab. Ganz verloren gehen die neuronalen und muskulären Reaktionen aber nicht. Zudem gelingt die Gewöhnung nicht immer. Ekel kann durch den Sensitivierungseffekt mit der Zeit sogar schlimmer werden.

\section{Perspektivwechsel kann helfen}

Der Beitrag beschreibt u.a. die Abwehr von Ekelgefühlen durch einen Perspektivwechsel. Wenn sich eklige Situationen nicht vermeiden lassen, kann man sich bewusst machen, dass die Nähe ein wesentlicher Faktor für das Ekelerleben ist. Meist verlieren Dinge ihren Ekel, wenn man sich ein Stück von ihnen entfernt. Auch die mentale Vorbereitung auf eine Situation kann helfen, etwa bei einer Darmuntersuchung, wo Blähungen oder unkontrollierte Darmentleerungen häufiger vorkommen.

Dazu gibt es viele praktische Tipps, die über das Tragen von Handschuhen oder Schutzkleidung hinausgehen. Der Einsatz von Pflegeschaum z. B. mindert nicht nur belastende Gerüche - mit ihm kann man auch eklig aussehende Substanzen verstecken.
In der „sprechstunde“ geht es um die Teamaufgabe Impfen: Patienten gezielt auf ihren Impfstatus anzusprechen, ist eine wichtige Aufgabe der Hausarztpraxis, denn hier laufen die Fäden der medizinischen Versorgung zusammen. Ein schöner Nebeneffekt ist dabei, dass die Leistungen extrabudgetär vergütet werden. „info praxisteam“ fasst die wichtigsten Punkte noch einmal zusammen. In der „praxisorganisation“ berichten Praxen über erste Erfahrungen mit dem neuen Medikationsplan. Ein Refresher fasst die To-Dos im DMP Koronare Herzkrankeit zusammen.

Dr. Reinhard Merz

\section{„info praxisteam“ im Web}

Unser MFA-Magazin erscheint viermal jährlich. Alle Beiträge sind unter

$$
\text { www.info-praxisteam.de }
$$

auch im Internet abrufbar und können direkt kommentiert werden.

Auch für mobile Endgeräte wie Smartphones oder Tablets ist "info praxisteam“ verfügbar. Die App wird sowohl für iOS von Apple als auch für Geräte mit Android-Plattform angeboten. Mehr darüber, wie man die App beziehen kann, erfahren Sie auf der oben angegebenen Website.

Zu den Beiträgen im Heft gibt es von der Redaktion ausgesuchte Verweise auf weiterführende Informationen online. Viele davon sind auch für Sie als Arzt interessant.

Sie erreichen uns per E-Mail unter:

redaktion@info-praxisteam.de 